\title{
Systematic review of the relationship between childcare educators' practices, and preschoolers' physical activity and eating behaviours
}

\author{
Stéphanie Ward, RD, MSc (Corresponding author) \\ $\mathrm{PhD}$ graduate student, Faculty of medicine and health sciences, Université de Sherbrooke \\ Centre de formation médicale du Nouveau-Brunswick \\ Pavillon J.-Raymond Frenette \\ 18 , rue des Aboiteaux \\ Moncton, NB \\ Canada E1A 3E9 \\ Phone: (506) 863-2273 \\ Email: Stephanie.ann.ward@usherbrooke.ca \\ Mathieu Bélanger, PhD. \\ Assistant Professor, Department of family medicine, Université de Sherbrooke \\ Director of research, Centre de formation médicale du Nouveau-Brunswick \\ Epidemiologist, Vitalité Health Network \\ Pavillon J.-Raymond Frenette \\ 18, rue des Aboiteaux \\ Moncton, NB \\ Canada E1A 3E9 \\ Phone: (506) 863-2221 \\ Email: Mathieu.f.belanger@usherbrooke.ca \\ Denise Donovan, MD, MPH \\ Associate Professor, Department of Community Health Sciences, Université de Sherbrooke \\ Centre de formation médicale du Nouveau-Brunswick \\ Pavillon J.-Raymond Frenette \\ 18, rue des Aboiteaux \\ Moncton, NB \\ Canada E1A 3E9 \\ Phone: (506) 863-2269 \\ Email: Denise.Donovan@usherbrooke.ca
}

Natalie Carrier, PhD.

Director and Associate Professor, École des sciences des aliments, de nutrition et d'études familiales, Université de Moncton

Pavillon Jacqueline-Bouchard

51 Antonine-Maillet Avenue

Moncton, NB

Canada E1A 3E9

Phone: 1 (506) 858-4003

Fax : 1 (506) 858-4283

Email : natalie.carrier@umoncton.ca 


\section{Keywords}

childcare centre, childcare educator, physical activity, eating behaviour

\section{Running title}

Review of childcare educators' practices

\section{Acknowledgements}

SW was supported by a Canadian Institutes of Health Research Charles Best Canada Graduate Scholarships Doctoral Award and by the Gérard-Eugène-Plante Doctoral Scholarship. The funders did not play a role in the design of the study, the writing of the manuscript or the decision to submit it for publication.

\section{Conflict of interest statement}

The authors declare no conflicts of interest. 


\section{Abstract}

The role of childcare educators is important given that $81 \%$ of preschoolers living in developed countries receive childcare outside their home. Since children learn by observing and imitating others, childcare educators may play a role in promoting healthy eating behaviours and physical activity in young children. Six databases were searched for quantitative peer-reviewed, English or French primary studies reporting the correlates, predictors or effectiveness of childcare educators' practices and behaviours on preschoolers' healthy eating and physical activity behaviours. Risk of bias was assessed using the Quality Assessment Tool for Quantitative Studies. Fifteen articles were included in this review: ten measured physical activity levels and five assessed eating behaviours. The quality score was rated as low for eight of these articles, and as moderate for the remaining seven. Two of four cross-sectional studies reported a positive relationship between educators and children's behaviours. Eleven intervention studies reported significant favourable effects of interventions. Educators may play a positive role in promoting healthy behaviours in children, but this is mainly based on studies of low or moderate qualityfew intervention type studies of low or moderate quality. The influence of specific components of educators' practices and behaviours on children's healthy eating and physical activity behaviours remains inconclusive.

\section{Introduction}

Childhood obesity has become a worldwide public health challenge, affecting approximately 43 million children under the age of 5 in 2010 [1]. The prevalence of overweight and obese children worldwide has increased from $4.2 \%$ to $6.7 \%$ since 1990 ; an increase that is expected to continue over the next decade [1]. Beyond being linked to an increased risk of remaining obese throughout childhood [2] and into adulthood [3], childhood obesity has been associated with immediate and long-term physical and emotional health problems [4-8]. 
In young children, obesity is primarily caused by an energy imbalance [9] which can be largely influenced by adults given the control they exert over the quality of children's diet and their exposure to opportunities to be physically active. Although parents tend to be the primary caregivers of children, approximately $81 \%$ of children between the ages of 3 and 5 living in developed countries receive childcare outside their home [10]. Although the average number of hours children spend in childcare varies considerably across countries [10], more than half of children in the United States and Canada spend an average of 30 hours a week in childcare [11,12]. Similarly, in a number of European countries, preschoolers are enrolled in formal childcare for an average of 30 hours or more per week [13]. Childcare centres could therefore be key settings for promoting healthy eating and physical activity behaviours in children, particularly in developed countries. The theory of observational learning suggests that children's behaviour is partly shaped by observing and mimicking the behaviour of others [14]. Behaviours modelled by educators in childcare centres may therefore have an important influence on the behaviours adopted by children $[15,16]$. Although some childcare-based nutrition and physical activity interventions have demonstrated positive outcomes on children's behaviours [17,18], little is known about how the social environment influences these behaviours.

Guidelines from the American Academy of Pediatrics, the American Public Health Association and the American Dietetic Association recommend that childcare educators provide opportunities for children to learn about food, practice and model healthy eating behaviours, have frequent conversations on trying and enjoying healthy foods, and to let children serve themselves during meals [19,20]. The American Dietetic Association also reinforces the importance of creating positive environments at mealtimes, which includes letting children decide what and how much to eat and not forcing children to finish their plate [19]. With regards to recommendations related to physical activity, the Centers for Disease Control and Prevention discourages withholding physical activities as means of punishment and encourages adults to actively participate in physical activities with children [21]. 
Some childcare educators' practices are aligned with guidelines, such as eating their lunch with children at mealtime, presenting new food enthusiastically, and structuring game-like lessons around food [22-24]. However, negative feeding practices have also been reported, including one study where over half of the 72 educators who completed the study questionnaire encouraged or forced children to eat specific desirable food items, not letting children decide how much to eat, using desserts as a reward for eating, and offering only foods they believe children like [25]. Other frequent negative feeding practices observed included not allowing children to feed themselves $[22,23,26]$, encouraging children to finish their plate and reprimanding children who did not eat all of their meal $[25,27,28]$.

Educators may be unaware of the role they can play in helping children become more physically active, and may unknowingly contribute to sedentary behaviours [29]. Educators in 96 childcare centres were observed using few prompts for physical activity and frequently withholding physical activities as punishment for bad behaviour [30]. Another qualitative study among 87 educators of 4- to 6-year-old children found that educators perceived preschoolers as sufficiently active and reported that children need to learn to sit still in order to prepare them for primary school [31].

The present review aims to identify if childcare educators' practices predict or are associated with

preschoolers' physical activity and eating behaviours in childcare centers and to assess the effectiveness of interventions that control educators' practices or behaviours in order to improve preschoolers' physical activity and eating behaviours.

\section{Methods}

\section{Protocol and registration}

The protocol for this review was published elsewhere [32] and describes the methodology used according to the Preferred Reporting Items for Systematic Reviews and Meta-Analyses (PRISMA) recommendations 
[33]. This review was also registered with the International prospective register of systematic reviews (PROSPERO) record CRD42014012973.

\section{Overview of methods}

Six electronic databases were searched: PubMed, The Cochrane Library, Science Direct, SportDiscus, CINAHL, and Wiley. The search strategy, including keywords and choice of databases, was developed in collaboration with an experienced librarian. Keywords, including physical activity, eating behaviour, obesity, childcare educator, and childcare centre, as well as their MeSH (medical subject heading) equivalents were used in various combinations and adapted to each database searched. Reference lists of eligible studies or of systematic reviews and meta-analyses were reviewed to ensure that all potentially eligible studies were retrieved. Eligible studies were peer-reviewed and original studies, published in either English or French, whose participants were preschoolers who received formal childcare by a non-relative. All types of quantitative study designs were eligible for this review, as to include all possible studies relating to the research topic. Also, included studies had to assess the unique contribution of childcare educators' practices or behaviours, on children's physical activity or eating behaviours. Therefore, multicomponent interventions, such as those which involved parents, modifications to the built environment or to policies, etc., or for which the study results could not be explained solely by the educators' practices or behaviours (e.g. the intervention was delivered in collaboration with nutrition or physical activity specialists, or no information was provided as to how physical activity sessions were delivered by educators), were excluded from this review. No publication date restrictions were used in any of the databases, and the search was completed in June 2015.

Once duplicates were removed, titles and abstracts were assessed independently by two authors (SW and MB), who then checked each other's references. The full texts of potentially eligible studies were retrieved and assessed against inclusion criteria by the first author (SW). A second review of the potentially eligible studies was then conducted by one of the three other authors (MB, DD and NC), who each reviewed one 
third of the articles. The first author extracted data from all articles, while the second, third and fourth authors each independently extracted data from one third of all included publications. Agreement between authors as to which study should be included in the review was high $(95.2 \%$ agreement; kappa $=0.818$; $\mathrm{p}<0.001)$ and disagreements were resolved through discussion among authors. The methodological quality of all the included studies was assessed by the first author using the Quality Assessment Tool for Quantitative Studies, developed by the Effective Public Health Practice Project (EPHPP) [34]. This tool was chosen because of its ability to assess the quality of various quantitative studyies designs relating to public health topics, and assesses the quality of the studies using six criteria: 1) selection bias, 2) study design, 3) confounders, 4) blinding, 5) data collection, and 6) withdrawals and dropouts [34]. Using the same method, the second, third and fourth authors each checked one third of the publications for completeness and accuracy of the quality assessment. Agreement between authors on the six items scored during the quality assessment was $100 \%(\mathrm{kappa}=1.0 ; \mathrm{p}<0.001)$.

Because of the heterogeneity of the study designs, outcomes, methods and measurement tools, metaanalyses were not feasible. Therefore, a systematic descriptive narrative synthesis was carried out. When study results were not expressed numerically, values were extracted from available figures. In order to draw overall conclusions a rating system of levels of evidence was used [35,36]. Strength of evidence was based on the study design, methodology assessment and consistency of results, and were determined as follows [36]: 1) strong evidence: at least two RCTs of high quality showing consistent results; 2) moderate evidence: at least one RCT of high quality, and at least one RCT of moderate or low quality or one quasiexperimental trial of high quality with consistent results; 3) weak evidence: only one RCT of high quality or multiple moderate to low-quality RCT, and quasi-experimental trials of high, moderate or low quality, all showing consistent results; and 4) insufficient evidence: only one low- or moderate-quality RCT or one high, moderate or low-quality quasi-experimental trial, or negative or contradictory outcomes of the studies. Results were considered to be consistent if at least two-thirds of the studies reported significant results in the same direction [35]. 


\section{Results}

Overall, 1342 studies emerged from the six search engines (PubMed, n=592; Cochrane Library, $\mathrm{n}=101$; Wiley, $n=322$; CINAHL, $n=217$; SportDiscus, $n=85$; Science Direct, $n=25$ ) and 48 additional studies were added after reviewing the lists of references (Figure 1). After removing duplicates, reviewing titles and abstracts and applying selection criteria, 15 articles were retained for this review.

\section{Methodological quality assessment of studies}

The quality score of each study assessed is presented in Table 1. Overall, eight studies (53\%) were rated as being of low methodological quality. Of the 10 physical activity-related papers, five papers received low ratings [37-41], while the other five were assessed as moderate [42-46]. Among the five studies that focused on nutrition, three were scored as low [47-49], while two received moderate ratings [50,51]. The Regardless of study designs, the low scores were primarily caused by low ratings attributed to the potential for selection bias, due to a lack of representativeness of the target population or low response rates, and because the tools for primary outcome measures were not described as valid, or were not reported in the study or in a separate study.

\section{Study characteristics}

Of the 15 studies, 14 were conducted in the United States, and one was from the Netherlands [40]. Most were RCTs, clustered RCTs or quasi-experimental trials [42-46,48,50,51]; three were pre-post design studies [38,47,49]; and four were cross-sectional [37,39-41]. Eight of the fifteen studies had fewer than 100 participants $[37,38,42,47-51]$, while six had between 101 and 500 participants [39-41,44-46], and only one had over 500 participants [43]. Participants were of low to middle socioeconomic status in four studies [42-44,47] and were primarily African American, Latino or Hispanic in six studies [42-46,48]. None of the remaining studies specified the ethnicity or socioeconomic status of the participating children. The number of childcare centres from which children were selected ranged from 1 to 45 centres. 
Of the 15 studies included in this review, 10 focused solely on physical activity [37-46] and 5 focused uniquely on nutrition [47-51]. None evaluated the two. Publication dates of studies that focused solely on physical activity outcomes ranged from 2008 to 2013, while almost all of the nutrition-related papers (4/5) were published in 2000 or earlier.

Of the physical activity-related papers, six assessed the effectiveness of interventions that required educators to instruct lessons on gross motor skills, actively participate in children's physical activities, and/or use various methods of encouraging children to be active (e.g. cueing children, giving performance feedback, giving pep talks) $[38,42-46]$. Four of these six papers [43-46] nevertheless assessed the same intervention amongst different populations and at different time points ( 8 weeks and 9 months), and amongst different sub-groups of the same target population, which was constituted of low to middle socioeconomic African American children. The remaining four physical activity-related papers assessed correlations between educators' behaviours and children's physical activity [37,39-41]. Educator behaviours included playing with children during play time, not restricting active play for children who misbehave, reading books or playing games with physical activity themes, initiating games and prompting children to be active.

The five nutrition-related papers assessed the effectiveness of educator practices during mealtime on children's food intake [47-51]. Practices assessed included the use of non-food rewards, encouraging children to "try one bite", choice offering (i.e. "Do you want any of this?"), silent and enthusiastic modelling, allowing children to self-select their food instead of serving pre-portioned foods, serving fruits and vegetables before other foods, and using positive verbal reinforcement.

All studies on physical activity assessed level of activity with objective measures, including accelerometers [41-46], and with direct observation by data collectors using the Observational System for Recording Physical Activity in Children - Preschoolers (OSRAC-P) [37-40]. In only one study were parents asked to complete a questionnaire related to their child's sedentary behaviour [42]. Similarly to the physical activity 
related studies, all studies on eating behaviours used objective methods to measure dietary intake - weighing or measuring plate waste [47-49] in three studies, and direct observation by data collectors $[47,48,50,51]$ in four studies.

\section{Relationship between educators' practices and physical activity of children}

\section{Cross sectional studies:}

Of the four cross-sectional studies that assessed the relationship between educator behaviours and physical activity, two found that providing portable play equipment every day, playing with children, and positively prompting children to be active were associated with more involvement in physical activity [40,41]. Although p-values were not reported, another cross-sectional study found that educator behaviours that promote physical activity were positively correlated with children's moderate-to-vigorous physical activity (MVPA) and total physical activity level, and inversely correlated with sedentary activity [37]. Other practices such as not restricting physical activity when children misbehave, and reading books or playing physical activity-themed games were not associated with children's physical activity [41]. It was also found that during outdoor play, child initiated activities were associated with more MVPA intervals than educator initiated activities, and that children were less likely to be active when educators were around [39].

\section{Experimental studies:}

Of the six papers that assessed the effectiveness of educator-led interventions, five were of moderate quality, including one small clustered randomised controlled trial [42], as well as two large clustered randomised controlled trial $[44,46]$ and three large quasi-experimental trials $[43,45]$. Four of these six studies assessed the effects of the same intervention in different samples. The sixth study was a small pre-

post design study of low quality [38] (Table 2). Five of the six studies reported a positive effect on children's MVPA [38,43-46]. The small study that did not find a positive effect on MVPA nevertheless reported a significant reduction in children's sedentary time [42]. Three of four studies reported an increase 
in vigorous physical activity (VPA) $[43,45,46]$, and one of two reported a significant reduction in light physical activity (LPA) [45].

Strength of evidence was based on only three RCTs, and two quasi-experimental studies of moderate quality, one low quality pre-post study, and four tow quality cross-sectional studies. Based on the strength of evidence evaluation, there is weak evidence that educators influence preschoolers' physical activity and sedentary behaviours.

\section{Relationship between educators' practices and healthy eating behaviours of children}

All five of the included papers reported positive changes in children's eating behaviours when educators used recommended meal-time practices. One small, moderate quality, quasi-experimental study found that children increased their intake of new foods (i.e. kiwi, sweet red pepper, chickpeas, and fresh coconut) when educators used non-food rewards [51], encouraged children to "try one bite" [51], and allowed children to self-select their food [51]. Although silent modelling was not shown to be effective in that study [51], another small, moderate quality, quasi-experimental study found that children's intake and acceptance of food increased when educators modelled healthy eating enthusiastically [50]. However, this effect was no longer observed when peer modelling was taken into consideration [50]. Two small, low quality, prepost design studies reported that children increased their intake of healthy snacks when educators allowed children to self-serve [47] and they increased their intake of vegetables when they gave immediate positive verbal reinforcement and giving a non-food reward [49]. Finally, one small, low quality, randomised crossover trial conducted primarily enamong African American children found that ehildren they ate more fruits and vegetables when they were allowed to serve themselves (also referred to as a family-style meal service), rather than pre-portioned, or when fruits and vegetables were served in advance of other menu items during a family-style meal service [48]. 
Given that three of the five studies were RCTs or quasi-experimental trials of low $(n=1)$ and moderate $(n=2)$ quality, and that results were consistent among two of these and two low quality pre-post studies, there is weak evidence that educator practices positively influence preschoolers' eating behaviours at this time.

\section{Discussion}

Our results suggest that educators may play a role in promoting healthy behaviours in children. However, the evidence for this is weak due to the dearth of high quality intervention studies. Given that specific practices or behaviours were heterogeneous, no single one was studied enough to draw conclusions. Further, more than half of the studies were of low quality and none was high. Also, Ssince most of the studies were conducted in the United States, the results may not be applicable in other high income countries, and probably not in low to middle income countries. Furthermore, the absence of cohort studies does not allow to draw conclusions on whether or not childcare educators' practices predict preschoolers' physical activity and eating behaviours in childcare centers. Nevertheless, almost all studies found that educators' practices and behaviours are positively associated with children's eating and physical activity behaviours. This is in line with the theory of observational learning, and highlights the potential for interventions to target childcare educators as role models for the promotion of healthy behaviours in preschoolers.

\section{Physical activity}

Of the six studies on physical activity interventions, five targeted primarily African Americans of low to middle socioeconomic status, and may therefore not be generalizable to other socioeconomic or ethnic groups.,

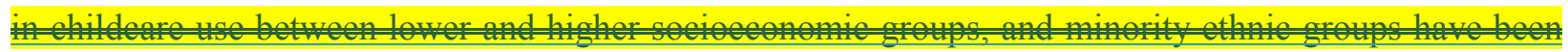

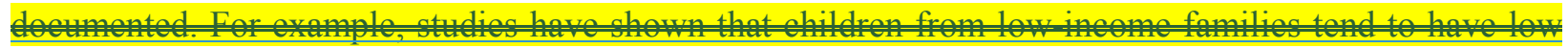

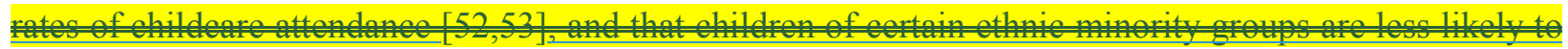
Heentre 
overestimate the potential effect of the intervention in other populations because both of these demographic markers are associated with low levels of physical activity. It has been reported that Black children tend to be less active than Caucasian children [58-60], and that low socioeconomic status is associated with $\underline{\underline{\text { lower }}}$ physical inactivity levels [61,62]. Therefore these populations may have greater room for physical activity improvement. Nonetheless, it should be noted that, compared to children from high-income families, children from low-income families tend to have lower rates of childcare attendance [52,53], and that children of some ethnic minority groups are also less likely to attend childcare [53-57]. Therefore, results from the studies included in this review may not accurately represent children from the lowest of low

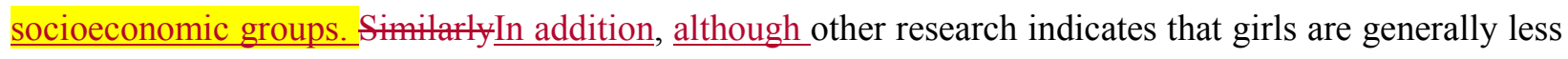
active than boys [63], butgender was not included in the analyses of these studies. and may therefore not be generalizable to other socioeconomic or ethnic groups. Firstly, disparities in childeare use between lower and higher socioeconomic groups, and minority ethnic groups have been documented. For example, studies have shown that children from low income families tend to have low rates of childeare attendance [52,53], and that children of certain ethnic minority groups are less likely to use centre based childeare [53 57$]$. Therefore, results from these studies may not accurately represent the lowest of low socioeconomic or ethnic minority children. Secondly,

Four studies that assessed the effectiveness of the Start for Life obesity prevention trial reported no significant changes in sedentary time, despite observing increases in MVPA and VPA [43-46]. This may be related to the timing of the physical activity intervention. Childcare programs for preschoolers typically include scheduled physical (i.e. free play) and non-physical activities (i.e. reading circles, crafts, puzzles) [64]. It is possible that these interventions are implemented at times when physical activities are already scheduled, so that the allocation of sedentary time remains unchanged while the intensity of the physical activity increases. Nevertheless, an increase in physical activity intensity is associated with health benefits $[65]$. 
Three of the four cross-sectional studies found some positive associations between physical activity promoting practices and children's physical activity levels $[37,40,41]$. Although active role modelling by adults is encouraged [66], the presence of educators may limit children's physical activity [39]. As suggested previously, this may be especially true for girls, who particularly enjoy being close to their educators [67]. Since educators are often inactive when they supervise, this may lead children, and especially girls, to be inactive [67]. Findings from this review suggest that there may lay a thin line between educators being over-involved and under-involved in physical activity promotion. It is possible that children who are generally less interested in being active could benefit more from educator-arranged activities and adult participation in physical activities, than children who are naturally very active, and for whom the presence and interaction of educators may act as a constraint. This could explain why certain interventions that focus on educator-led activities do not have a positive effect on children's percentage of time spent in physical activity [42]. Future studies should examine how specific educator practices impact active and less active children, as well as boys and girls differentially.

\section{Healthy eating behaviours}

Most nutrition-related studies, in addition to being small, were carried out more than 14 years ago. Since children's diet and food environments have changed considerably in the last decades [68-74], the studies may not be applicable today. Furthermore, most studies measured children's eating behaviours by direct observation which can be highly subjective and can. Also, this method-lacks precision at the individual level [75]. New, more reliable methods of assessment of children's food intake have since evolved-been used [76]. It is also important to notenoteworthy that only one of these studies specified the socioeconomic status of the sample (middle SES) [47] and one, while anereported the ethnicity of the children (African American) [48]. This type of information is important to assess the generalisability of these interventionsfindings, as low socioeconomic status and certain minority ethnicities have been linked to poor diets of poorer quality $[77,78]$. 
In accordance with the theory of observational learning [14], significant relationships between educators' positive meal-time practices and children's eating behaviours were found in all five nutrition-related studies. Results from two quasi-experimental studies found that silent modelling from educators may not be enough to increase children's intake or acceptance of foods [50,51]. A subsequent study found that when educators practiced enthusiastic modelling, children increased their acceptance of new foods but that this effect lost significance when peer modelling was taken into account [50]. Using rewards, encouraging children to "try one bite" or offering children the choice of tasting a food were more effective in encouraging children to taste that food compared to silent modelling [51]. However, using rewards to encourage children to eat has been debated, because the effect may not last longer than the offer of the reward $[79,80]$. Despite these findings, it has been suggested that verbal rewards are better than tangible rewards, and that rewards should be given according to the quality of the behaviour rather than the quantity of the behaviour [81].

Letting children serve themselves was found to be conducive to increasing fruit and vegetable intake in one study [48]. This practice is based on the notion that young children have the ability to self-regulate their food intake based on the energy density of the foods consumed and their energy needs [82], and that restrictive feeding methods (e.g. pre-portioning meals) may diminish children's self-regulation abilities [83]. Furthermore, since it has been documented that children with higher adiposity show less selfregulation than children with lower adiposity [83], it may be important to promote self-regulation.

\section{Gaps in the evidence}

Interventions promoting physical activity in childcare centres included in this review focused largely on a homogenous population - African-Americans of low socioeconomic status, thus limiting the reachpotential generalisability of these interventions to children of other socioeconomic and ethnic groups. While this is a group at risk of not achieving recommended levels of physical activity [58-60], further evidence related to other sectorsegments of the population is required as the level of physical activity can vary by gender, culture and other population attributes [84]. Similarly, research into interventions to improve the eating 
behaviours of preschoolers lack consideration of demographic differences between groups [85]. In addition to differences in childcare use, health disparities also exist among socioeconomic and ethnic groups [86]. Consequently, determining best practices to use to improve healthy eating and physical activity interventions in childeare centres may inadvertently perpetuate health inequalities between socioeconomic and ethnic groups. Therefore, although childeare centres may be a great place to promote healthy behaviours in a large proportion of the population, one should also consider intervening in places that will help reach marginalized groups, such as people of low socioeconomic status and ethnic minority.

As most of the studies relating to nutrition in this review date from 2000 and earlier, there is a need to reassess the-interventions in today's changed environment and with modern-more reliable measures. Further, since children are highly influenced by other individuals who are similar to them (i.e. peers) [14], it might also be useful to assess how peers' eating behaviours (e.g. picky eaters or overeaters) impact other children's food intake.

Health-related behaviours learned in childhood are likely to persist into adolescence and adulthood [87,88], but the contribution of educators' practices on this persistence is undocumented. Longitudinal studies are required to assess contributions of children's different environments on their later eating and physical activity behaviours. Further, although childcare centres may represent an excellent setting to promote healthy behaviours in a large proportion of the population, program planners should also consider intervening in places that will help reach marginalized groups, such as people of low socioeconomic status and ethnic minority, which may be underrepresented in childcare settings (REFERENCES 52-57). Ignoring this may inadvertently contribute to widening the already apparent health disparities existing among socioeconomic and ethnic groups [86].

\section{Methodology quality}

Limitations relating to the lack of representativeness of the target population and lack of reporting of response rates were common across most studies, regardless of their design. The latter is common in 
epidemiological studies, where it has been reported that a substantial number of peer-reviewed studies do not provide information on study participation [89]. Information was also lacking on the randomization procedures, and whether outcome assessors and/or participants were blinded. Although blinding reduces the risk for information bias, it has been reported that many studies do not properly report their blinding efforts, therefore reducing the readers' ability to judge its effect on bias reduction [90]. Another limitation was the lack of reporting of the validity of outcome measurement tools. Ten of the fifteen studies (67\%) did not report whether the data collection tools were valid, including all of the nutrition-related outcome measures. It has been said that the use of valid tools to measure physical activity and diet is problematic in epidemiological studies [91,92], as these are often costly and impractical on a population basis [92].

Strengths of this review included the detailed systematic approach for searching articles, the use of validated tools for assessing methodology quality, and not restricting the publication period. Some limitations nevertheless must be acknowledged. The heterogeneity in the study designs, outcomes, methods and measurement tools, made comparisons difficult; therefore data were narratively synthesized and described. There is also a risk of reporting bias since the review involved the judgments of the authors. However, this limitation was mitigated by having two independent assessors at every stage of the review.

\section{Conclusion}

This review provides a systematic summary of empirical studies that have examined the relationship between childcare educators' practices and children's eating and physical activity behaviours. It appears that educators may play a role in promoting healthy behaviours among preschoolers in childcare centres. However, because of the lack of high quality intervention studiesbody of evidence and the low quality of the existing studies, the influence of specific practices on children's healthy eating and physical activity behaviours remains inconclusive. This lack of evidence is a barrier to providing evidence-based best practices for educators to use in childcare centres. 
Future research should look at filling the gaps identified in this review by assessing previously-studied practices of educators on larger, more diverse populations and conducting analyses on subgroups of children, for instance according to gender, activity level and body weight, and assessing the effectiveness of other recommended practices, such as including physical activity in time periods typically devoted to sedentary activities (e.g. reading circles), involving children in the preparation of food or having frequent informal discussions regarding food. The methodological quality of studies should also be improved by ensuring representativeness, reporting on the blinding of outcome assessors, conducting or increasing the length of follow-ups, using valid, reliable and objective measurement tools, as well as ensuring that the validity and reliability of these tools are reported.

\section{Conflict of interest statement}

The authors declare no conflicts of interest.

\section{Acknowledgements}

SW was supported by a Canadian Institutes of Health Research Charles Best Canada Graduate Scholarships Doctoral Award and by the Gérard-Eugène-Plante Doctoral Scholarship. The funders did not play a role in the design of the study, the writing of the manuscript or the decision to submit it for publication. 


\section{References}

1. De Onis M, Blossner M, Borghi E. Global prevalence and trends of overweight and obesity among preschool children. Am J Clin Nutr 2010; 92:1257-1264.

2. Quattrin T, Liu E, Shaw N, Shine B, Chiang E. Obese children who are referred to the pediatric endocrinologist: characteristics and outcome. Pediatrics 2005; 115:348-351.

3. Guo S, Huang C, Maynard L, et al. Body mass index during childhood, adolescence and young adulthood in relation to adult overweight and adiposity: the Fels longitudinal study. Int J Obes Relat Metab Disord 2000; 24:1628-1635.

4. Freedman D, Dietz W, Srinivasan S, Berenson G. The relation of overweight to cardiovascular risk factors among children and adolescents: the Bogalusa Heart Study. Pediatrics 1999; 103:1175-1182.

5. Park M, Falconer C, Viner R, Kinra S. The impact of childhood obesity on morbidity and mortality in adulthood: a systematic review. Obes Rev 2012; 13:985-1000.

6. Reilly J, Kelly J. Long-term impact of overweight and obesity in childhood and adolescence on morbidity and premature mortality in adulthood: systematic review. Int $J$ Obes 2011; 35:891-898.

7. Friedemann C, Heneghan C, Mahtani K, Thompson M, Perera R, Ward A. Cardiovascular disease risk in healthy children and its association with body mass index: systematic review and meta-analysis. BMJ 2012; 345:E4759-E4775.

8. Institute of Medicine, Committee on Prevention of Obesity in Children and Youth. Extent and consequences of childhood obesity. In: Koplan J, Liverman C, Kraak V (eds). Preventing childhood obesity: health in the balance. Library of Congress Cataloging-in-Publication Data: Washington, 2005, pp. 54-58.

9. Centers for Disease Control and Prevention. (2013) Overweight and obesity; childhood overweight and obesity, contributing factors [WWW document]. URL http://www.cdc.gov/obesity/childhood/problem.html

10. Organisation for economic co-operation and development. (2013) PF3.2 Enrolment in childcare and pre-schools [WWW document]. URL http://www.oecd.org/els/soc/PF3_2_Enrolment_in_childcare_and_preschools.pdf

11. Eunice Kennedy Shriver National Institute of Child Health and Human Development, NIH, DHHS. The NICHD Study of Early Child Care and Youth Development (SECCYD): Findings for Children up to Age 4 1/2 Years. Government Printing Office: Washington, 2006. 
12. Sinha M. (2014) Spotlight on Canadians: Results from the General Social Survey: Child care in Canada [WWW document]. URL http://www.statcan.gc.ca/pub/89-652-x/89-652x2014005-eng.pdf

13. European Commission. (2009) The provision of childcare services: a comparative review of 30 European countries [WWW document] URL http://ec.europa.eu/social/main.jsp?langId=en\&catId=89\&newsId=545\&

14. Bandura A. Social learning theory. Prentice Hall: Englewood Cliffs, NJ, 1977.

15. Nicklas T, Baranowski T, Baranowski J, Cullen K, Rittenberry L, Olvera N. Family and childcare provider influences on preschool children's fruit, juice and vegetable consumption. Nutr Rev 2001; 59:224-235.

16. Larson N, Ward D, Neelon S, Story M. What role can child-care settings play in obesity prevention? A review of the evidence and call for research efforts. J Am Diet Assoc 2011; 111:1343-1362.

17. Mikkelsen M, Husby S, Skov L, Perez-Cueto F. A systematic review of types of healthy eating interventions in preschools. Nutr $J 2014 ; 13: 56-64$.

18. Temple M, Robinson J. A systematic review of interventions to promote physical activity in the preschool setting. $J$ Spec Pediatr Nurs 2014; 19:274-284.

19. Benjamin Neelon SE, Briley ME, American Dietetic Association. Position of the American Dietetic Association: benchmarks for nutrition in child care. J Am Diet Assoc 2011; 111:607615.

20. American Academy of Pediatrics, American Public Health Association, National Resource Center for Health and Safety in Child Care. Caring for our children: National health and safety performance standards: guildelines for early care and education programs. $3^{\text {rd }}$ edn. Elk Grove Village, IL; Academy of Pediatrics: Washington, 2011.

21. Centers for Disease Control and Prevention. Guidelines for school and community programs to promote lifelong physical activity among young people. MMWR Recomm Rep 1997; 46:136.

22. Sigman-Grant M, Christiansen E, Branen L, Fletcher J, Johnson S. About feeding children: mealtimes in child-care centers in four Western states. J Am Diet Assoc 2008; 108:340-346.

23. Trost S, Messner L, Fitzgerald K, Roths B. Nutrition and physical activity policies and practices in family child care homes. Am J Prev Med 2009; 37:537-540.

24. Lumeng J, Kaplan-Sanoff M, Shuman S, Kannan S. Head Start teachers' perceptions of children's eating behavior and weight status in the context of food scarcity. J Nutr Educ Behav 2008; 40:237-243. 
25. Freedman M, Alvarez K. Early childhood feeding: assessing knowledge, attitude, and practices of multi-ethnic child-care providers. J Am Diet Assoc 2010; 110:447-451.

26. Nahikian-Nelms M. Influencial factors of caregiver behavior at mealtime. $J$ Am Diet Assoc 1997; 97:505-509.

27. Gable S, Lutz S. Nutrition socialization experiences of children in the Head Start program. $J$ Am Diet Assoc 2001; 101:572-577.

28. Ramsay S, Branen L, Fletcher J, Price E, Johnson S, Sigman-Grant M. “Are you done?” Child care providers' verbal communication at mealtimes that reinforce or hinder children's internal cues of hunger and satiation. $J$ Nutr Educ Behav 2010; 42:265-270.

29. Copeland KA, Kendeigh CA, Saelens BE, Kalkwarf HJ, Sherman SN. Physical activity in child-care centers: do teachers hold the key to the playground? Health Educ Res 2012; 27:81100 .

30. McWilliams C, Ball S, Benjamin S, Hales D, Vaughn A, Ward D. Best-practice guidelines for physical activity at child care. Pediatrics 2009; 124:1650-1659.

31. De Craemer M, De Decker E, De Bourdeaudhuij I, et al. Physical activity and beverage consumption in preschoolers: focus groups with parents and teachers. BMC Public Health 2013; 13:278-290.

32. Ward S, Bélanger M, Donovan D, Horsman A, Carrier N. Correlates, determinants, and effectiveness of childcare educators' practices and behaviours on preschoolers' physical activity and eating behaviours: a systematic review protocol. Syst Rev 2015; 4:18-23.

33. Moher D, Liberati A, Tetzlaff J, Altman D. Preferred reporting items for systematic reviews and meta-analyses: The PRISMA statement. BMJ 2009; 339:B2535.

34. National Collaboration Center for Methods and Tools. (2008) Quality Assessment Tool for Quantitative Studies. [WWW document]. URL http://www.nccmt.ca/registry/view/eng/14.html

35. Van Sluijs E, McMinn A, Griffin S. Effectiveness of interventions to promote physical activity in children and adolescents: systematic review of controlled trials. Br Med J. 2007; 335:703715 .

36. Van Sluijs E, van Poppel M, van Mechelen W. Stage-based lifestyle interventions in primary care: are they effective? Am J Prev Med. 2004; 26:330-343.

37. Bower J, Hales D, Tate D, Rubin D, Benjamin S, Ward D. The childcare environment and children's physical activity. Am J Prev Med 2008; 34:23-29. 
38. Brown W, Googe H, McIver K, Rathel J. Effects of teacher-encouraged physical activity on preschool playgrounds. $J$ Early Interv 2009; 31:126-145.

39. Brown W, Pfeiffer K, Mciver K, Dowda M, Addy C, Pate R. Social and environmental factors associated with preschoolers' non-sedentary physical activity. Child Dev 2009; 80:45-58.

40. Gubbels J, Kremers S, van Kann D, et al. Interaction between physical environment, social environment, and child characteristics in determining physical activity at child care. Heal Psychol 2011; 30:84-90.

41. Gunter KB, Rice KR, Ward DS, Trost SG. Factors associated with physical activity in children attending family child care homes. Prev Med 2012; 54:131-133.

42. Alhassan S, Nwaokelemeh O, Ghazarian M, Roberts J, Mendoza A, Shitole S. Effects of locomotor skill program on minority preschoolers' physical activity levels. Pediatr Exerc Sci 2012; 24:435-449.

43. Annesi J, Smith A, Tennant G. Effects of a cognitive-behaviorally based physical activity treatment for 4- and 5-year-old children attending US preschools. Int J Behav Med 2013; 20:562-566.

44. Annesi J, Smith A, Tennant G. Effects of the Start For Life treatment on physical activity in primarily African American preschool children of ages 3-5 years. Psychol Heal Med 2013; 18:300-309.

45. Annesi J, Smith A, Tennant G. Reducing high BMI in African American preschoolers: effects of a behavior-based physical activity intervention on caloric expenditure. South Med J 2013; 106:456-459.

46. Annesi J, Smith A, Tennant G. Cognitive-behavioural physical activity treatment in AfricanAmerican pre-schoolers: effects of age, sex, and BMI. J Paediatr Child Health 2013; 49:E128-132.

47. Branen L, Fletcher J. Effects of restrictive and self-selected feeding on preschool children's food intake and waste at snacktime. J Nutr Educ 1994; 26:273-277.

48. Harnack L, Oakes J, French S, Rydell S, Farah F, Taylor G. Results from an experimental trial at a Head Start center to evaluate two meal service approaches to increase fruit and vegetable intake of preschool aged children. Int J Behav Nutr Phys Act 2012; 9:51-58.

49. Ireton C, Guthrie H. Modification of vegetable-eating behavior in preschool children. J Nutr Educ 1972; 4:100-103.

50. Hendy HM, Raudenbush B. Effectiveness of teacher modeling to encourage food acceptance in preschool children. Appetite 2000; 34:61-76. 
51. Hendy H. Comparison of five teacher actions to encourage children's new food acceptance. Ann Behav Med 1999; 21:20-26.

52. Tang S, Coley RL, Votruba-Drzal E. Low-income families' selection of child care for their young children. Child Youth Serv Rev 2012; 34:2002-2011.

53. Zachrisson H, Janson H, Nærde A. Predicting early center care utilization in the context of universal access. Early Child Res $Q 2013 ; 28: 74-82$.

54. Vandenbroeck M, De Visscher S, Van Nuffel K, Ferla J. Mothers' search for infant child care: The dynamic relationship between availability and desirability in a continental European welfare state. Early Child Res $Q$ 2008; 23:245-258.

55. Fuller B, Holloway S, Liang X. Family selection of child-Care centers: The influence of household support, ethnicity, and parental practices. Child Dev 1996; 67:3320-3337.

56. Liang X, Fuller B, Singer J. Ethnic differences in child care selection: The influence of family structure, parental practices, and home language. Early Child Res $Q 2000 ; 15: 357-$ 384 .

57. Radey M, Brewster K. The influence of race/ethnicity on disadvantaged mother's child care arrangements. Early Child Res Q 2007; 22:379-393.

58. Eyre ELJ, Duncan MJ. The impact of ethnicity on objectively measured physical activity in children. ISRN Obes 2013; 2013:1-15.

59. Kristjansdottir G, Vihjalmsson R. Sociodemographic differences in patterns of sedentary and physically active behavior in older children and adolescents. Acta Paediatr 2001; 90:429-435.

60. McVeigh J, Norris S, de Wet T. The relationship between socioeconomic status and physical activity patterns in South African children. Acta Paediatr 2004; 93:982-988.

61. Lämmle L, Worth A, Bös K. Socio-demographic correlates of physical activity and physical fitness in German children and adolescents. Eur J Public Health 2012; 22:880-884.

62. Drenowatz C, Eisenmann JC, Pfeiffer KA, et al. Influence of socio-economic status on habitual physical activity and sedentary behavior in 8- to 11-year old children. BMC Public Health 2010; 10:214-224.

63. Vale S, Silva P, Santos R, Soares-Miranda L, Mota J. Compliance with physical activity guidelines in preschool children. $J$ Sports Sci 2010; 28:603-608.

64. Bredekamp S, Copple C (eds). Developmentally appropriate practice in early childhood programs. 3rd edn. National Association for the Education of Young Children: Washington, DC, 2009. 
65. Warburton D, Nicol C, Bredin S. Health benefits of physical activity: the evidence. CAMJ 2006; 17:801-809.

66. Canadian Sport for Life. (2011) Helping children play - The adult role [WWW document]. URL http://canadiansportforlife.ca/active-start/helping-children-play-\%E2\%80\%93-adultrole-2

67. Cardon G, Cauwenberghe E, Labarque V, Haerens L, De Bourdeaudhuij I. The contribution of preschool playground factors in explaining children's physical activity during recess. Int $J$ Behav Nutr Phys Act 2008; 5:11-16.

68. Slining M, Mathias K, Popkin B. Trends in food and beverage sources among US children and adolescents: 1989-2010. J Acad Nutr Diet 2013; 113:1683-1694.

69. Piernas C, Popkin B. Food portion patterns and trends among U.S. children and the relationship to total eating. $J$ Nutr $2011 ; \mathbf{1 4 1}: 1159-1164$.

70. Piernas C, Popkin B. Increased portion sizes from energy-dense foods affect total energy intake at eating occasions in US children and adolescents : patterns and trends by age group and sociodemographic characteristics. Am J Clin Nutr 2011; 94:1324-1332.

71. Harris J, Schwartz M, Munsell C, et al. (2013) Fast food FACTS 2013: Measuring progress in nutrition and marketing to children and teens [WWW document]. URL http://www.fastfoodmarketing.org/media/FastFoodFACTS_report.pdf

72. Powell L, Szczypka G, Chaloupka F. Trends in exposure to television food advertisements among children and adolescents in the United States. Arch Pediatr Adolesc Med 2010; 164:794-802.

73. Guthrie J, Lin B, Frazao E. Role of food prepared away from home in the American diet, 197778 versus 1994-96: changes and consequences. J Nutr Educ Behav 2002; 34:140-150.

74. Adair L, Popkin B. Are child eating patterns being transformed globally? Obes Res 2005; 13:1281-1299.

75. Australasian Child \& Adolescent Obesity Research Network. (2010) Dietary intake assessment - Direct Observation [WWW document]. URL http://www.acaorn.org.au/streams/nutrition/assessment-methods/direct-observation.php

76. Long JD, Littlefield LA, Estep G, et al. Evidence review of technology and dietary assessment. Worldviews Evid Based Nurs 2010; 7:191-204.

77. Drewnowski A, Specter S. Poverty and obesity : the role of energy density and energy costs. Am J Clin Nutr 2004; 79:6-16. 
78. Darmon N, Drewnowski A. Does social class predict diet quality? Am J Clin Nutr 2008; 87:1107-1117.

79. Lepper M, Greene D, Nisbett R. Undermining children's intrinsic interest with extrinsic reward: A test of the "overjustification" hypothesis. J Pers Soc Psychol 1973; 28:129-137.

80. Dickinson AM. The detrimental effects of extrinsic reinforcement on "Intrinsic motivation". Behav Anal 1989; 12:1-15.

81. Eisenberger R, Cameron J. Detrimental effects of reward: Reality or myth? Am Psychol 1996; 51:1153-1166.

82. Birch LL, Deysher M. Caloric compensation and sensory specific satiety: evidence for self regulation of food intake by young children. Appetite 1986; 7:323-331.

83. Johnson S, Birch L, McPhee L. Parents' and children's adiposity and eating style. Pediatrics 1994; 94:653-661.

84. Hinkley T, Crawford D, Salmon J, Okely A, Hesketh K. Preschool children and physical activity: a review of correlates. Am J Prev Med 2008;34:435-441.

85. Lorson B, Melgar-Quinonez H, Taylor C. Correlates of fruit and vegetable intakes in US children. J Am Diet Assoc 2009; 109:474-478.

86. Meyer P, Penman-Aguilar A, Campbell VA, et al. Conclusion and future directions: CDC Health Disparities and Inequalities Report - United States, 2013. MMWR Surveill Summ 2013; 62:184-186.

87. Telama R, Yang X, Leskinen E, et al. Tracking of physical activity from early childhood through youth into adulthood. Med Sci Sports Exerc 2014; 46:955-962.

88. Mikkla V, Rasanene L, Raitakari O, et al. Consistent dietary patterns identified from childhood to adulthood: the cardiovascular risk in Young Finns Study. Br Jounral Nutr 2005; 93:923931.

89. Morton L, Cahill J, Hartge P. Reporting participation in epidemiologic studies: a survey of practice. Am J Epidemiol 2006; 163:197-203.

90. Schulz K, Grimes D. Blinding in randomised trials: hiding who got what. Epidemiol Ser 2002; 359:696-700.

91. Livingstone M, Robson P, Wallace J. Issues in dietary intake assessment of children and adolescents. Br J Nutr 2007; 92:S213-222.

92. Laporte R, Montoye H, Caspersen C. Assessment of physical activity in epidemiologic research : Problems and prospects. Public Heal Rep 1985; 100:131-146. 


\section{Table and figure legends}

Figure 1: PRISMA flow diagram of study selection process

Table 1: Characteristics of included studies

Table 2: Summary of study results 
Table 1 Characteristics of included studies

\begin{tabular}{|c|c|c|c|c|c|c|}
\hline Paper (reference) & Country & Study design & Study population & Main objective(s) & $\begin{array}{l}\text { PA or diet outcome } \\
\text { measurement tools }\end{array}$ & $\begin{array}{l}\text { Quality* } \\
\text { Score }\end{array}$ \\
\hline \multicolumn{7}{|c|}{ Physical activity-related studies } \\
\hline $\begin{array}{l}\text { Bower et al. } 2008 \\
\text { [37] }\end{array}$ & United States & Cross-sectional & $\begin{array}{l}80 \text { children } \\
20 \text { childcare centres }\end{array}$ & $\begin{array}{l}\text { To examine the relationship } \\
\text { between the social and built } \\
\text { environment of childcare } \\
\text { centres and physical activity of } \\
\text { children. }\end{array}$ & Observation OSRAC-P & Low \\
\hline $\begin{array}{l}\text { Brown et al. } 2009 \\
\text { [38] }\end{array}$ & United States & Pre-, post design & $\begin{array}{l}5 \text { children } \\
2 \text { university-affiliated } \\
\text { childcare centres }\end{array}$ & $\begin{array}{l}\text { To enhance young children's } \\
\text { moderate-to-vigorous physical } \\
\text { activity on playgrounds through } \\
\text { a teacher-implemented } \\
\text { intervention. Baseline } \\
\text { observations were conducted on } \\
7 \text { to } 14 \text { days, while intervention } \\
\text { observations were conducted on } \\
3 \text { to } 6 \text { days, depending on the } \\
\text { child assessed. }\end{array}$ & Observation OSRAC-P & Low \\
\hline $\begin{array}{l}\text { Brown et al. } 2009 \\
\text { [39] }\end{array}$ & United States & Cross sectional & $\begin{array}{l}476 \text { children } \\
24 \text { childcare centres }\end{array}$ & $\begin{array}{l}\text { To describe which social and } \\
\text { environmental events were } \\
\text { predictors of MVPA and } \\
\text { sedentary activity of children } \\
\text { during outdoor play. }\end{array}$ & Observation OSRAC-P & Low \\
\hline $\begin{array}{l}\text { Gubbels et al. } 2011 \\
\text { [40] }\end{array}$ & Netherlands & Cross sectional & $\begin{array}{l}175 \text { children } \\
9 \text { childcare centres }\end{array}$ & $\begin{array}{l}\text { To investigate the link } \\
\text { between childcare environment } \\
\text { and PA of children. }\end{array}$ & Observation OSRAC-P & Low \\
\hline $\begin{array}{l}\text { Gunter et al. } 2012 \\
{[41]}\end{array}$ & United States & Cross sectional & $\begin{array}{l}136 \text { children } \\
45 \text { family childcare } \\
\text { centres }\end{array}$ & $\begin{array}{l}\text { To examine the relationship } \\
\text { between family childcare home } \\
\text { practices and characteristics, } \\
\text { and children's physical activity. }\end{array}$ & Accelerometers & Low \\
\hline
\end{tabular}




\begin{tabular}{|c|c|c|c|c|c|c|}
\hline $\begin{array}{l}\text { Alhassan et al. } \\
2012 \text { [42] }\end{array}$ & United States & Clustered RCT & $\begin{array}{l}71 \text { children } \\
\text { Low SES; primarily } \\
\text { Latino/Hispanic and } \\
\text { African American } \\
2 \text { childcare centres }\end{array}$ & $\begin{array}{l}\text { To examine the effect of a } \\
\text { classroom, teacher-taught, } \\
\text { locomotor skill-based PA } \\
\text { program on the locomotor skills } \\
\text { and physical activity levels of } \\
\text { minority preschoolers. } \\
\text { Data were collected at baseline } \\
\text { and } 6 \text { months after the initiation } \\
\text { of the intervention. }\end{array}$ & $\begin{array}{l}\text { Accelerometers } \\
\text { Parent questionnaire }\end{array}$ & Moderate \\
\hline $\begin{array}{l}\text { Annesi et al. } 2013 \\
\text { [43] }\end{array}$ & United States & Quasi-experimental & $\begin{array}{l}885 \text { children } \\
\text { Low to middle SES, } \\
\text { primarily African } \\
\text { American } \\
98 \text { childcare } \\
\text { classrooms }\end{array}$ & $\begin{array}{l}\text { To assess the effect of the } 9 \text { - } \\
\text { month Start for Life trial on } 4 \\
\text { to } 5 \text { year old African American } \\
\text { preschoolers' PA and BMI. } \\
\text { Data were collected at months } \\
1,5 \text { and } 9 \text { after the initiation of } \\
\text { the intervention. }\end{array}$ & Accelerometers & Moderate \\
\hline $\begin{array}{l}\text { Annesi et al., } 2013 \\
{[44]}\end{array}$ & United States & Clustered RCT & $\begin{array}{l}338 \text { children } \\
\text { Low to middle SES, } \\
\text { primarily African } \\
\text { American } \\
7 \text { childcare centres; } \\
19 \text { classes }\end{array}$ & $\begin{array}{l}\text { To assess the effect of the Start } \\
\text { for Life obesity prevention trial } \\
\text { on } 3 \text { to } 5 \text { year old African } \\
\text { American preschoolers' PA and } \\
\text { BMI. } \\
\text { Data were collected at baseline } \\
\text { and } 8 \text { weeks after the initiation } \\
\text { of the intervention. }\end{array}$ & Accelerometers & Moderate \\
\hline $\begin{array}{l}\text { Annesi et al. } 2013 \\
{[45]}\end{array}$ & United States & Quasi-experimental & $\begin{array}{l}273 \text { children } \\
\text { African American } \\
\text { children } \\
17 \text { childcare } \\
\text { classrooms }\end{array}$ & $\begin{array}{l}\text { To assess the effect of the } 9 \text { - } \\
\text { month Start for Life trial on } 4 \\
\text { to } 5 \text { year old African American } \\
\text { preschoolers' PA and BMI. } \\
\text { Data were collected at baseline } \\
\text { and } 9 \text { months after the initiation } \\
\text { of the intervention. }\end{array}$ & Accelerometers & Moderate \\
\hline
\end{tabular}


Annesi et al. 2013 United States [46]
275 children

African American

children

32 childcare

classrooms
To assess the effect of the Start Accelerometers

for Life obesity prevention trial

on African American

preschoolers' PA and BMI.

Data were collected at baseline

and 8 weeks after the initiation

of the intervention.

Nutrition-related studies

Branen \& Fletcher, United States

1994 [47]

Harnack et al. 2012 United States

[48]
Pre-, post design with 40 children

age-group comparison

Middle SES

1 childcare

centre

RCT with crossover

53 children

Primarily African

American

1 childcare

centre
To compare food intake and

waste of 3 and 4 year old

children at snack time when

educators give one standard

portion of a snack and when

children are allowed to self-

select the amount. Educators

gave standard portions of

snacks for 29 days. Children

were allowed to self-select the

portion for 25 days.

To evaluate the effects of serving fruits and vegetables first, serving meals portioned and plated by educators on

children's intake of fruits and

vegetables. The provider

portioned, fruits and vegetables

first, and control conditions

were each evaluated on two

randomly chosen weeks, for a

total study length of six weeks.
Low

Waste measurements with

household measuring tools

Observation
Plate waste
Observation
Waste measurements with
household measuring tools




\begin{tabular}{|c|c|c|c|c|c|c|}
\hline $\begin{array}{l}\text { Ireton \& Guthrie } \\
1972 \text { [49] }\end{array}$ & United States & Pre-, post design & $\begin{array}{l}19 \text { children } \\
1 \text { childcare } \\
\text { centre }\end{array}$ & $\begin{array}{l}\text { To measure the effectiveness } \\
\text { of varying preparation methods } \\
\text { and using tokens as a reward on } \\
\text { children's consumption of } \\
\text { cooked vegetables. Each } \\
\text { experimental periods lasted } \\
\text { three weeks }\end{array}$ & Weighed plate waste & Low \\
\hline $\begin{array}{l}\text { Hendy \& } \\
\text { Raudenbush } 2000 \\
{[50]}\end{array}$ & United States & Quasi-experimental & 97 children & $\begin{array}{l}\text { To compare acceptance of } \\
\text { four familiar foods by } \\
\text { preschool children across three } \\
\text { lunches, with foods presented } \\
\text { under either silent teacher } \\
\text { modelling or simple exposure. }\end{array}$ & Observation & Moderate \\
\hline Hendy 1999 [51] & United States & Quasi-experimental & $\begin{array}{l}64 \text { children } \\
19 \text { childcare centres }\end{array}$ & $\begin{array}{l}\text { To compare the effectiveness } \\
\text { of adult mealtime actions to } \\
\text { encourage children's } \\
\text { acceptance of novel foods } \\
\text { across three consecutive days. }\end{array}$ & Observation & Moderate \\
\hline
\end{tabular}

* Quality score based on the Quality Assessment Tool for Quantitative Studies

RCT : randomized controlled trial; SES : socioeconomic status; PA: physical activity; BMI: Body mass index; OSRAC-P: Observational System for Recording Activity of Children - Preschool version; MVPA: moderate-to-vigorous physical activity. 


\section{Table 2 Summary of study results}

\section{PHYSICAL ACTIVITY}

\section{Effectiveness}

Study

Relationship assessed

nadjusted mean difference

Adjusted mean difference

(p value)

Result summary

Brown et al. $\quad$ MVPA (reference $=$ non- $\quad \Delta 56.6 \%$ between conditions $\quad \mathrm{N} / \mathrm{R}$

2009 [38] intervention days)

(1)

On days when teachers guided discussions of $\mathrm{PA}$, gave pep talks, participated in PA, encouraged and acknowledged children's PA, children increased their MVPA on intervention days relative to non-intervention days.

\begin{tabular}{|c|c|c|c|c|}
\hline $\begin{array}{l}\text { Alhassan et al. } \\
2012 \text { [42] }\end{array}$ & $\begin{array}{l}\text { During Preschool PA : } \\
\text { Sedentary PA } \\
\text { Light PA } \\
\text { MVPA } \\
\text { Total Daily PA: } \\
\text { Sedentary PA } \\
\text { Light PA } \\
\text { MVPA }\end{array}$ & $\begin{array}{l}\mathrm{N} / \mathrm{R} \\
\mathrm{N} / \mathrm{R} \\
\mathrm{N} / \mathrm{R}\end{array}$ & $\begin{array}{l}\Delta-9.6 \%(\mathrm{p}=0.02) \text { over } 6 \text { months between groups } \\
\Delta 2.9 \%(\mathrm{p}=0.19) \text { over } 6 \text { months between groups } \\
\Delta 3.4 \%(\mathrm{p}=0.13) \text { over } 6 \text { months between groups }\end{array}$ & $\begin{array}{l}\text { When educators instructed lessons on gross } \\
\text { motor skills, children decreased their \% of } \\
\text { time spent in sedentary PA at preschool and } \\
\text { over the total day, compared to children in the } \\
\text { control group. } \\
\text { No effects on } \% \text { of time spent in light PA or } \\
\text { MVPA. }\end{array}$ \\
\hline $\begin{array}{l}\text { Annesi et al. } \\
2013 \text { [43] }\end{array}$ & $\begin{array}{l}\text { Sedentary activity } \\
\text { MPVA } \\
\text { VPA }\end{array}$ & $\begin{array}{l}\Delta-0.7 \%(\mathrm{p} \geq 0.05) \text { over } 9 \text { months between groups } \\
\Delta 1.4 \%(\mathrm{p}=0.016) \text { over } 9 \text { months between groups } \\
\Delta-1.8 \%(\mathrm{p}<0.001) \text { over } 9 \text { months between groups }\end{array}$ & $\begin{array}{l}N / R \\
N / R \\
N / R\end{array}$ & $\begin{array}{l}\text { When educators instructed lessons on gross } \\
\text { motor skills, used cues, gave performance } \\
\text { feedback and helped children set goals and } \\
\text { self-monitor, children spent more time in } \\
\text { MPVA and VPA than usual practice centres. }\end{array}$ \\
\hline $\begin{array}{l}\text { Annesi et al., } \\
2013 \text { [44] }\end{array}$ & $\begin{array}{l}\text { Sedentary activity } \\
\text { MVPA } \\
\text { VPA }\end{array}$ & $\begin{array}{l}\text { N/R } \\
\text { N/R } \\
\text { N/R }\end{array}$ & $\begin{array}{l}\Delta-2.3 \%(\mathrm{p}=0.162) \text { over } 8 \text { weeks between groups } \\
\Delta 2.77 \%(\mathrm{p}=0.026) \text { over } 8 \text { weeks between groups } \\
\Delta 2.0 \%(\mathrm{p}=0.058) \text { over } 8 \text { weeks between groups }\end{array}$ & $\begin{array}{l}\text { When educators instructed lessons on gross } \\
\text { motor skills, used cues, gave performance } \\
\text { feedback and helped children set goals and } \\
\text { self-monitor, children increased their time } \\
\text { spent in MVPA compared to usual practice } \\
\text { centres. }\end{array}$ \\
\hline
\end{tabular}




\begin{tabular}{|c|c|c|c|c|}
\hline $\begin{array}{l}\text { Annesi et al. } \\
2013 \text { [45] }\end{array}$ & $\begin{array}{l}\text { Sedentary activity } \\
\text { Light PA } \\
\text { MPA } \\
\text { MVPA } \\
\text { VPA }\end{array}$ & $\begin{array}{l}\mathrm{N} / \mathrm{R}(\mathrm{p} \geq 0.05) \text { over } 9 \text { months between groups } \\
\Delta-4.8 \%(\mathrm{p}<0.001) \text { over } 9 \text { months between groups } \\
\mathrm{N} / \mathrm{R}(\mathrm{p} \geq 0.05) \text { over } 9 \text { months between groups } \\
\Delta 2.0 \%(\mathrm{p}=0.031) \text { over } 9 \text { months between groups } \\
\Delta 2.1 \%(\mathrm{p}<0.001) \text { over } 9 \text { months between groups }\end{array}$ & $\begin{array}{l}\text { N/R } \\
\text { N/R } \\
\text { N/R } \\
\text { N/R } \\
\text { N/R }\end{array}$ & $\begin{array}{l}\text { When educators instructed lessons on gross } \\
\text { motor skills, used cues, gave performance } \\
\text { feedback and helped children set goals and } \\
\text { self-monitor, children spent more time in } \\
\text { MPVA and VPA and less time in light PA, } \\
\text { compared to usual practice centres. }\end{array}$ \\
\hline $\begin{array}{l}\text { Annesi et al. } \\
2013 \text { [46] }\end{array}$ & $\begin{array}{l}\text { Sedentary activity } \\
\text { MVPA } \\
\text { VPA }\end{array}$ & $\begin{array}{l}\Delta-1.84 \%(\mathrm{p} \geq 0.05) \text { over } 8 \text { weeks between groups } \\
\Delta 2.65 \%(\mathrm{p}=0.013) \text { over } 8 \text { weeks between groups } \\
\Delta 1.8 \%(\mathrm{p}=0.037) \text { over } 8 \text { weeks between groups }\end{array}$ & $\begin{array}{l}\text { N/R } \\
\text { N/R } \\
\text { N/R }\end{array}$ & $\begin{array}{l}\text { When educators instructed lessons on gross } \\
\text { motor skills, used cues, gave performance } \\
\text { feedback and helped children set goals and } \\
\text { self-monitor, children increased their time } \\
\text { spent in MVPA and VPA, compared to usual } \\
\text { practice centres. }\end{array}$ \\
\hline
\end{tabular}

\section{Correlates}

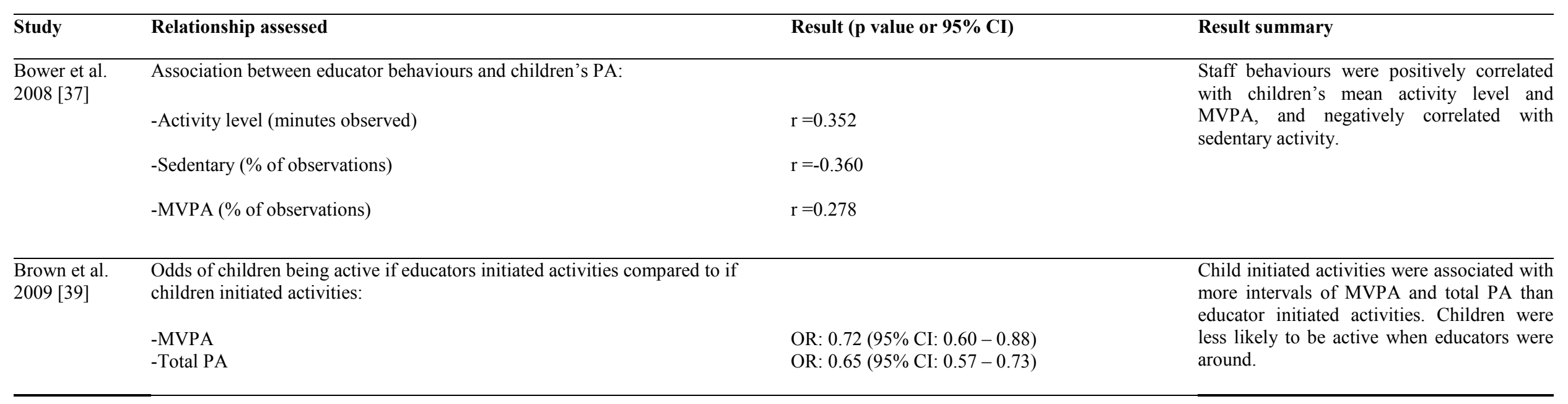


Odds of children being active alone, with one peer, or with a group of peers, if

educators were present compared to if they were not present:

- Alone:

MVPA

Total PA

OR:0.28 (95\% CI: $0.25-0.32)$

One-on-one with peers:

MVPA

LMVPA

Group without educator:

MVPA

OR:0.44 $(0.38-0.50)$

OR: 0.65 (95\% CI: $0.59-0.72)$

LMVPA

OR:0.49 $(0.45-0.55)$

OR: 0.68 (95\% CI: $0.63-0.72)$

Gubbels et al. Association between positive and negative prompting on children's PA:

$2011[40]$

- Positive prompts (reference $=$ no prompts)

Indoor activity intensity

Outdoor activity intensity

$\mathrm{r}=0.37(\mathrm{p}<0.001)$

$\mathrm{r}=0.39(\mathrm{p}<0.01)$

- Negative prompts (reference $=$ no prompts)

Indoor activity intensity

$\mathrm{r}=0.12(\mathrm{p} \geq 0.05)$

Outdoor activity intensity

$\mathrm{r}=-0.05(\mathrm{p} \geq 0.05)$

Gunter et al. Difference between total PA (min/hour) of children in PA promoting

2012 [41] environments vs. children in non-PA environments as characterized by:

-Educators never restricts active play time for children who misbehave

$\Delta-0.1(\mathrm{p}=0.94)$

- Educators often or always plays with children during active (free) play time

$\Delta 2.5(\mathrm{p}=0.013)$

-Educators read books and play games with PA or exercise themes

$\Delta 0.0(\mathrm{p}=0.94)$

Positive prompting by staff had a positive influence on children's PA intensity both indoor and outdoor. Negative prompting by staff did not influence children's PA intensity.

Children engaged in more minutes of total activity/hour when educators often or always played with children during active free play time. Not restricting active play for children who misbehave, and reading books an playing games with PA or exercise themes were not associated with greater activity/hour in family childcare homes. 


\section{EATING BEHAVIOURS}

\section{Effectiveness}

Study Relationship assessed

Unadjusted mean difference

(p value)

$\Delta 0.87(\mathrm{p}<0.01)$ between conditions

$\Delta 0.03(\mathrm{p} \geq 0.05)$ between conditions

$\Delta 2.7(\mathrm{p} \geq 0.05)$ between conditions

\section{Adjusted mean difference Result summary}

(p value)
$\mathrm{N} / \mathrm{R}$

$\mathrm{N} / \mathrm{R}$
Children increased their intake of snacks when teachers allowed children to self-select compared to when they pre-portioned food.

Number of wasted portions did not significantly differ between pre-portioning food and allowing children to self-serve.

Grams of waste did not significantly differ between both feeding methods.

\begin{tabular}{|c|c|}
\hline & $\begin{array}{l}\text { Fruits and vegetables served first } \\
\text { (reference = in tandem with other foods) } \\
\text { Fruits (mean serving) } \\
\text { Vegetables, no potatoes (mean serving) } \\
\text { Grains (mean serving) } \\
\text { Meat (mean serving) } \\
\text { Milk (mean serving) } \\
\text { Energy (kcal) } \\
\text { Fat (\%kcal) } \\
\text { Fibre (g) } \\
\text { Vitamin A (RAE in mcg) } \\
\text { Vitamin C (mg) } \\
\text { Folate (DFE, mcg) } \\
\text { Educator portioned (reference = family-style service) } \\
\text { Fruits (mean serving) } \\
\text { Vegetables, no potatoes (mean serving) } \\
\text { Grains (mean serving) } \\
\text { Meat (mean serving) } \\
\text { Milk (mean serving) } \\
\text { Energy (kcal) } \\
\text { Fat (\%kcal) } \\
\text { Fibre (g) } \\
\text { Vitamin A (RAE in mcg) } \\
\text { Vitamin C (mg) } \\
\text { Folate (DFE, mcg) }\end{array}$ \\
\hline
\end{tabular}

$\Delta 0.08(\mathrm{p}<0.01)$ between conditions $\Delta 0.02(\mathrm{p}>0.05)$ between conditions $\Delta 0.02(\mathrm{p} \geq 0.05)$ between conditions $\Delta-0.05(\mathrm{p} \geq 0.05)$ between conditions $\Delta-0.04(\mathrm{p} \geq 0.05)$ between condition $14.4(\mathrm{p} \geq 0.05)$ between conditions $\Delta 1.1(\mathrm{p} \geq 0.05)$ between conditions $\Delta 0.2(\mathrm{p} \geq 0.05)$ between conditions $\Delta 367.2(\mathrm{p}<0.01)$ between conditions $\Delta 1.3(\mathrm{p}>0.05)$ between conditions $\Delta 4.2(\mathrm{p}<0.05)$ between conditions

$\Delta-0.07(\mathrm{p}<0.001)$ between conditions $\Delta-0.03(\mathrm{p}<0.01)$ between conditions $\Delta 0.08(\mathrm{p}<0.05)$ between conditions $\Delta 0.49(\mathrm{p}<0.001)$ between conditions $\Delta 0.06(\mathrm{p}<0.01)$ between conditions $\Delta 61.5(\mathrm{p}<0.001)$ between conditions $\Delta 2.4(\mathrm{p}<0.001)$ between conditions $\Delta 0.3(\mathrm{p}<0.05)$ between conditions $\Delta-3.6(\mathrm{p}<0.01)$ between conditions $\quad \mathrm{N} / \mathrm{R}$ $\Delta 9.5(\mathrm{p}<0.001)$ between conditions $\quad \mathrm{N} / \mathrm{R}$ $228.4(\mathrm{p} \geq 0.05)$ between conditions $\quad \mathrm{N} / \mathrm{R}$
When educators served fruits and vegetables in advance of other menu items during a traditional family-style meal service, children consumed more fruit and increased their intake of vitamin A and folate, than when all

When educators pre-portioned meals, children ate more grains, meat and milk, and increased their intake in calories, \% calories from fat, fibre and folate, compared to when meals were served family-style.

Children ate less fruits and vegetables (excluding potatoes), and decreased their intake in vitamin $\mathrm{C}$ when meals were preportioned rather than served family-style. items were served in tandem. 


\begin{tabular}{|c|c|c|c|}
\hline $\begin{array}{l}\text { Ireton \& Guthrie, -Giving immediate positive reinforcement } \\
\text { (reference }=\text { no positive reinforcement) } \\
\text { Asparagus (grams) } \\
\qquad \begin{array}{l}\text { Broccoli (grams) } \\
\text { Cauliflower (grams) } \\
\text { Spinach (grams) } \\
\text { Squash (grams) }\end{array}\end{array}$ & $\begin{array}{l}\Delta 14.06(\mathrm{p}<0.001) \text { between conditions } \\
\Delta 21.88(\mathrm{p}<0.01) \text { between conditions } \\
\Delta 15.63(\mathrm{p}<.0 .02) \text { between conditions } \\
\Delta 10.47(\mathrm{p}<0.001) \text { between conditions } \\
\Delta 20.78(\mathrm{p}<0.01) \text { between conditions }\end{array}$ & $\begin{array}{l}\mathrm{N} / \mathrm{R} \\
\mathrm{N} / \mathrm{R} \\
\mathrm{N} / \mathrm{R} \\
\mathrm{N} / \mathrm{R} \\
\mathrm{N} / \mathrm{R}\end{array}$ & $\begin{array}{l}\text { Mean intakes of all vegetables were higher } \\
\text { when educators gave immediate positive } \\
\text { reinforcement (verbal and use of a sticker) } \\
\text { than when educators did not give positive } \\
\text { reinforcement. }\end{array}$ \\
\hline $\begin{array}{l}\text {-Silent modelling }(\text { reference }=\text { simple exposure }) \\
\text { Number of familiar foods } \\
\text { Number of new foods } \\
\text {-Enthusiastic modelling (reference }=\text { simple exposure) } \\
\text { Bites of new food }\end{array}$ & $\begin{array}{l}\Delta-0.305(\mathrm{p} \geq 0.05) \text { between groups } \\
\Delta 0.024(\mathrm{p} \geq 0.05) \text { between groups }\end{array}$ & $\begin{array}{l}\mathrm{N} / \mathrm{R} \\
\mathrm{N} / \mathrm{R}\end{array}$ & $\begin{array}{l}\text { Silent modelling was not effective in } \\
\text { increasing children's intake of familiar or new } \\
\text { foods across meals compared to simple } \\
\text { exposure. } \\
\text { Enthusiastic modelling was effective in } \\
\text { increasing number of bites taken of new foods, } \\
\text { compared to simple exposure. }\end{array}$ \\
\hline $\begin{array}{l}\text { Hendy } 1999 \text { [51] - Modelling (reference = simple exposure) } \\
\text { Number of foods } \\
\text { Number of meals } \\
\text { Number of bites } \\
\text { - } \text { Rewarding (reference = simple exposure) } \\
\text { Number of foods } \\
\text { Number of meals } \\
\text { Number of bites } \\
\text {-Insisting (reference }=\text { simple exposure) } \\
\text { Number of foods } \\
\text { Number of meals } \\
\text { Number of bites } \\
\text {-Choice-offering (reference = simple exposure) } \\
\text { Number of foods } \\
\text { Number of meals } \\
\text { Number of bites }\end{array}$ & $\begin{array}{l}\Delta 2.45(\mathrm{p}<0.001) \text { between groups } \\
\Delta 1.5(\mathrm{p}<0.001) \text { between groups } \\
\Delta 11.55(\mathrm{p}<0.002) \text { between groups }\end{array}$ & $\begin{array}{l}\mathrm{N} / \mathrm{R} \\
\mathrm{N} / \mathrm{R} \\
\mathrm{N} / \mathrm{R}\end{array}$ & $\begin{array}{l}\text { Using rewards, insisting that children "try one } \\
\text { bite" and choice-offering were more effective } \\
\text { than simple exposure to food to encourage } \\
\text { number of foods, number of meals and } \\
\text { number of bites taken. Modelling was } \\
\text { ineffective compared to simple exposure. }\end{array}$ \\
\hline
\end{tabular}

MPA: Moderate physical activity; MVPA: Moderate-to-vigorous physical activity; N/R: results not reported; PA: Physical activity; VPA: Vigorous physical activity: 